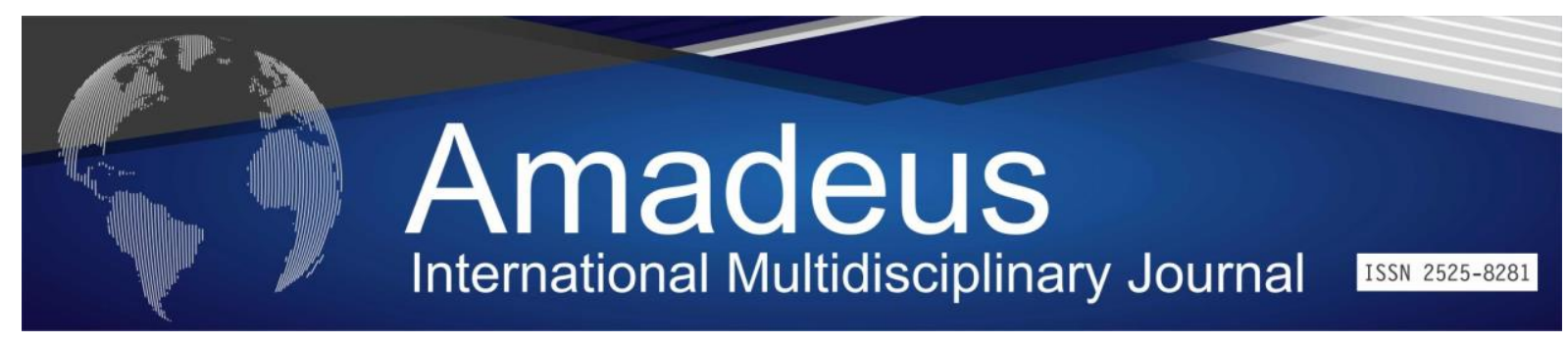

DOI: 10.14295/aimj.v5i9.146

\title{
The Importance of Laboral Rest in Maintenance of Worker's Mental Health: A Systematic Review
}

Aline Mesquita da Costa ${ }^{1}$ Thércia Lucena Grangeiro Maranhão ${ }^{2}$

\begin{abstract}
This article aims to make a systematic review on the Importance of Work Rest in the Maintenance of Metal Worker's Health, it was observed that the intensification of the working day can be harmful to mental health and consequently its quality of life. The guiding question is: what is the importance of homes for maintaining workers' mental health? The research was carried out through the methodology of systematic review and aims to: Study the relationship between the intervals to improve the quality of life of the worker; Analyze factors that contribute to the maintenance of the worker's mental health; Understand the damage that exhaustive periods of work can bring to workers' lives.
\end{abstract}

Key words: Workday, rest, workload, quality of life, worker health, labor legislation

\section{A Importância do Repouso Laboral na Manutenção da Saúde Metal do Trabalhador: Uma Revisão Sistemática}

\begin{abstract}
Resumo: O estudo teve como objetivo principal refletir sobre a importância dos repousos na manutenção da saúde mental do trabalhador e tem como objetivos específicos: Estudar a relação entre os intervalos para a melhoria da qualidade de vida do trabalhador; Analisar fatores que contribuem para a manutenção da saúde mental do trabalhador; Compreender os prejuízos que períodos exaustivos de trabalho podem trazer para a vida dos trabalhadores.A pesquisa foi realizada através de da metodologia de revisão sistemática da literatura
\end{abstract}

Palavras Chaves: Jornada De Trabalho, Descanso, Carga Horária Qualidade De Vida, Saúde Do Trabalhador, Legislação Trabalhista.

\footnotetext{
${ }^{1}$ Concludente do Curso de MBA de Gestão de Pessoas do UNINTA. E- mail: alinemc_88@hotmail.com;

${ }^{2}$ Prof ${ }^{a}$ Orientadora. Docente do curso de Psicologia da UNINTA. Mestra em Ciências da Saúde pela Faculdade de Medicina do ABC-FMABC. E-mail: therciapsicologa@gmail.com.
} 


\section{Introdução}

Percebe-se na atualidade a intensificação da jornada de trabalho como uma das crescentes indutoras de mal-estar social, agravando problemas à saúde dos trabalhadores (Pina; Stotz, 2015)

Segundo Carneiro e Ferreira, (2007) com a redução da Jornada de trabalho há uma melhora na qualidade de vida do trabalhador fora do expediente, pois o mesmo passa a ter mais tempo para a família, a saúde e demais atividades necessárias para manutenção da qualidade de vida, assim o trabalhador consegue ter melhor aproveitamento de tempo e maior concentração em suas atividades laborais, o autor deixa claro que o tempo de trabalho não é a única esfera que deve ser observada para a qualidade de vida.

É importante ter clareza sobre o assunto para que possamos reduzir o desenvolvimento de doenças ocupacionais e possíveis acidentes de trabalho. Longas jornadas de trabalho dispõe de uma maior probabilidade em conduzir a doenças ocupacionais e acidentes de trabalho, que corresponderá segundo Santos et al, (2017) ao cansaço, ao desgaste físico, mental e as alterações biológicas do organismo.

Refletindo sobre o tema surgiu a pergunta de partida: Qual a importância dos repousos para a manutenção a saúde mental do trabalhador? Pensando-se em responder tal problema o estudo tem como objetivo principal refletir sobre a importância dos repousos na manutenção da saúde mental do trabalhador e tem como objetivos específicos: Estudar a relação entre os intervalos para a melhoria da qualidade de vida do trabalhador; Analisar fatores que contribuem para a manutenção da saúde mental do trabalhador; Compreender os prejuízos que períodos exaustivos de trabalho podem trazer para a vida dos trabalhadores.

O interesse pessoal no tema do estudo se deu da vivência dos pesquisadores em rotinas trabalhistas, no qual foi percebido desinteresse e desmotivação dos empregados que exerciam longas jornadas de trabalho.

O estudo é pertinente pois apresenta outros questionamentos sobre o tema, não com a pretensão de esgotar o assunto, mas para estimular estudos futuros e novos aprofundamentos , para desenvolver uma compreensão mais ampla sobre a questão apresentada. A partir dos resultados imediatos pretende-se contribuir com novas reflexões relacionadas a saúde do trabalhador por profissionais da área que podem gerar sensibilização para mudança das relações entre empregado e empregador. 


\section{Fundamentação Teórica}

\section{Jornadas de Trabalho}

Segundo os Descritores em Ciências da Saúde (DeCS) jornada de trabalho significa quantidade de dias de atividade de trabalho compreendidas em uma semana ou em um mês (DeCS, 2017)

Segundo Coimbra (2016), os repousos são importantes na medicina e segurança do trabalho, como forma de proteção a dignidade, a saúde e a vida do trabalhador e está a segurada na constituição do Brasil. A necessidade em se limitar o tempo de trabalho surgiu durante a revolução industrial, mas o direito do trabalhador como "jornada de trabalho, descanso semanal remunerado, intervalos e férias, só começa a acontecer após a Revolução Francesa (1789)" (Coimbra,2016,p 191.), As mas condições de trabalho geraram reinvindicações para coibir abusos dos empregadores, durante a segunda fase da Revolução Industrial, quando Karl Max e Friedrich Engels, em seu livro "Manifesto do partido comunista" expos ao mundo a desordem e a violência que os trabalhadores experienciavam. Coimbra (2016), fala da importância do papel da igreja católica que reconhecia através de suas Encíclicas, a injustiça social e afirmava que o numero de horas trabalhadas não deveria exceder as forças do trabalhador e que os trabalhadores deviam descansar no dia do senhor e reconhecia que o estado deveria intervir nesta relação entre empregado e empregador, pois no modelo de estado liberal clássico permitia-se autonomia das partes sem intervenção do estado, o que acabava por acontecer de os trabalhadores trabalharem do nascer ao se por do sol o que o autor usa as palavras de Mario de la Cueva, de jornada máxima.

As jornadas de trabalho antes da primeira guerra mundial eram exaustivas nas quais $o$ autor demonstra da seguinte forma:

Na maioria dos países da Europa, por volta de meados de 1800, a jornada de trabalho era de 12 a 16 horas, principalmente entre mulheres e menores. Nos Estados Unidos da América, no mesmo período, a jornada de trabalho estava balizada entre 11 e 13 horas. Na Inglaterra, em 1847, foi fixada a jornada em 10 horas; em Paris, 11 horas. Em 1868, nos Estados Unidos, a jornada foi determinada em 8 horas no serviço público federal, tudo conforme Sérgio Pinto Martins. Na América Latina, o Chile foi o primeiro a estabelecer o limite de 8 horas para os trabalhadores estatais (1908), seguindo de Cuba, em 1909, para os mesmos empregados, e do Uruguai em 1915 $\frac{35}{\text {. A }}$ partir de 1915 foi se generalizando a jornada de oito horas na maioria dos países, após diversos movimentos dos trabalhadores, inclusive greves (Coimbra, 2016, p.193) 
Foi no tratado de Versalhes em 1919, no fim da primeira guerra mundial que se passou a não se admitir tratar o trabalho humano como mercadoria e estabeleceu a jornada de trabalho de 8 horas diárias e 48 horas semanais em seguida várias convenções adotaram o tempo de trabalho, a Convenção de n. ${ }^{\circ} 30$ de 1930 teve seu destaque:

A Convenção n. ${ }^{\circ}$ 30, de 1930, estabelece a jornada de 8 horas para os trabalhadores do Comércio e dos Escritórios; a Convenção n. 31 fixa em 7h45min a jornada dos trabalhadores das minas de carvão; a Convenção n. ${ }^{\circ} 40$, de 1935, propõe a redução da carga semanal para 40 horas; a Convenção n. ${ }^{\circ}$ 47, de 1935, propõe a redução da carga semanal para 35 horas, num período em que o mundo se encontrava devastado pela crise econômica e pela guerra.(Coimbra, 2016, p.194)

Na chamada era Getúlio Vargas na constituição 1988, houve a inovação da redução de 48 horas para 44 horas semanais além de abrir a possibilidade de facultar a compensação de horas, a redução da jornada de trabalho e introduziu jornada de seis horas para o trabalho realizado em turnos ininterruptos de revezamento (Coimbra, 2016).

\section{Interjornadas}

A interjornada e a intrajornada são dois tipos de descansos que acontecem durante a jornada de trabalho (Bellintani, 2019), segundo os Descritores em Ciências da Saúde (DeCS) descanso ou repouso em português significa liberdade de atividade (DeCS, 2017).

Bellintani, 2019, nos traz em seu artigo a explicação clara e sucinta de que a interjornada, conhecida como intervalo entre jornadas é o intervalo entre o fim de uma jornada e inicio de outra, acessegurada no artigo 66 da Consolidação das Leis trabalhistas, CLT, é um intervalo de tempo importante que possibilita a socialização, fortalecimento de vínculos familiares, o descanso, manutenção da saúde e segurança do trabalhador. Mesmo a Lei sendo clara sobre sua duração de onze horas consecutivas no mínimo a empregadores que não demonstram credibilidade a importância deste intervalo para a qualidade de vida do trabalhador, assim, acabam por dividi-lo ou diminui-la.

Como dito anteriormente no descritor, descanso ou repouso em português significa liberdade de atividade (DeCS , 2017). O que abre a possibilidade para o empregador, pratique outras atividades que são de bastante importância para a saúde do trabalhador como os que serão citados.

Segundo Costa, (2020), o sono é muito importante para a manutenção da saúde e da qualidade de vida, principalmente o sono noturno, a perda de sono mesmo que parcial poderá 
acarretar distúrbios de sono ou de vigília, o que por consequência pode levar a hipertensão, obesidade, depressão e até mesmo a morte.

Segundo Silva et all, (2019), o trabalho noturno na área da enfermagem acontece em grande frequência, sendo assim os mesmos tem grande privação de sono.

Com isso, pode haver possíveis repercussões no cuidado prestado e à saúde do trabalhador, como a possibilidade de interferência na agilidade, qualidade do atendimento e ocorrência de acidentes de trabalho, sugerindo reflexos na segurança do paciente e na qualidade do atendimento. (SILVA ET ALL, 2019, P.3) .

A falta de sono pode causar sonolência diurna no qual a pessoa senti dificuldades de se manter acordado durante o período diurno o que vem a atrapalhar suas atividades diárias como dirigir , trabalhar, socializar e quando o mesmo acontece no trabalho coloca em risco não só a vida o trabalhador como de quem está a sua volta no caso dos enfermeiros a vida de seus pacientes (Silva et all, 2019).

Outro exemplo de como o sono é importante pode ser analisado pelo estudo de Pellegrino e Marqueze, (2019), sobre pilotos de avião que apresentam diversos problemas com de sono e de saúde devido as grandes cargas laborais e as mudanças nas escalas de trabalho, o que ocasiona cochilos, sonolência durante o trabalho, os mesmos também não conseguiam tirar mais do que 150 minutos para atividade física.

Segundo Jeronimo et all, (2014), a atividade física trás grandes benefícios tanto a saúde mental como a saúde física, promove qualidade de vida no trabalho.

[...]trabalhadores com níveis de atividade física mais elevados apresentam menor peso corporal, maior consumo de frutas e vegetais, menor consumo de tabaco e melhor bem-estar mental ${ }^{3}$. Nesse sentido, a área da atividade física e saúde vem pesquisando outras temáticas em saúde pública como a saúde do trabalhador (Jeronimo et al., 2019, p. 2657).

Segundo Cunha, (2020), praticar atividades físicas regularmente é importante para prevenção de hipertensão arterial, proporciona melhoras em doenças arteriais coronariana, diabetes, dislipidemias, disfunção renal, depressão, doença pulmonar obstrutiva, osteoartrite, entre outras.

\section{Intrajornadas}

A intrajornada como citado anteriormente, é o descanso concedido no percorrer da jornada de trabalho, tendo duração de 15 minutos para quem trabalha de 4 a 6 horas por dia e 
de 1 hora no mínimo para quem trabalha 8 horas diárias podendo ser reduzido para meia hora caso o Ministério do trabalho autorize ( Bellintani, Nathalia, 2019). A intenção deste intervalo é tornar o trabalho menos exaustivo, na busca de garantir a segurança e saúde do trabalhador, mesmo sendo prescrito por lei há empresas que as desrespeitam. (Bellintani, Nathalia, 2019)

Machado (2018), demonstra a sua preocupação com o tempo de intrajornada conhecido como o repouso para descanso ou almoço, já que a pouco tempo a legislação trabalhista deu a possibilidade de que este intervalo fosse de no mínimo meia hora, em seu artigo, o autor demonstra a preocupação em relação ao tempo destinado a alimentação, ao descanso e o seu deslocamento ao local além do tempo para ser atendidos. demonstrando que o mesmo acaba por ser insuficiente para ser realizado de maneira adequada, por conta do tempo ser insuficiente acaba por fazer com que os trabalhadores passem a consumir comidas prontas e fast food o que pode vir a aumentar o índice de pessoas com sobrepeso e obesidade, caso haja a necessidade da adoção dos 30 minutos de intrajornada é importante que a empresa disponibilize um refeitório, mas que a mesma esteja ciente de que a falta de opções também podem dificultar a adesão a uma alimentação saudável.

\section{Saúde Mental}

Segundo os Descritores em Ciências da Saúde (DeCS) saúde mental significa Bemestar emocional, psicológico e social de um indivíduo ou grupo. (DeCS, 2017)

Segundo Gaiano (2018) devido um contexto histórico turbulento e complexos conceitos, a saúde mental inicialmente era vista como um campo apenas da medicina e gradualmente o cuidado com a saúde de forma multidisciplinar foi incorporado ao da saúde mental, o mesmo afirma que a definição de saúde como um estado de completo bem-estar físico, mental e social, não sendo apenas reduzido a apenas a ausência de doenças, demonstra a inovação no conceito de saúde, que acaba por englobar a saúde mental, ou seja a saúde mental está relacionada a subjetividade e a cultura, está ligado a habilidade que o sujeito desenvolveu para lidar com adversidades do cotidiano.

Porem Gama (2014), nos traz a observação de que esse conceito de um bem estar por completo tem bastante críticas por demonstra ser inalcançável, a saúde mental é algo complexo e não se reduz a normal e patológico. 


\section{Saúde Física e Mental do Trabalhador}

Segundo Silva-Junior e Fischer, (2015), entre as principais causas de afastamentos temporários no trabalho está relacionado a transtornos mentais e comportamentais.

Tais quadros são frequentes e comumente incapacitantes, evoluindo com absenteísmo pela doença e redução de produtividade. Nos últimos anos o adoecimento mental se manteve como a terceira principal causa de concessão de benefício auxílio-doença por incapacidade laborativa no Brasil. Mais de 203 mil novos benefícios foram concedidos por ano, sendo que $6,25 \%$ foram considerados pela perícia previdenciária como relacionados ao trabalho. Uma publicação conjunta da Organização Internacional do Trabalho (OIT) e da Organização Mundial da Saúde (OMS) chamou a atenção para a relevância da relação entre fatores psicossociais no trabalho e repercussão sobre a saúde dos trabalhadores. Condições de exposição crônica a estressores psicossociais desfavoráveis no trabalho estão associadas a queixas psicossomáticas, sintomas psiquiátricos e mudanças no bem-estar (Silva-Junior, Fischer, 2015, p.736).

Segundo os Descritores em Ciências da Saúde (DeCS) saúde física e mental do trabalhador é a Promoção e manutenção no mais alto grau do bem-estar físico, mental e social dos trabalhadores em todas as ocupações; a prevenção entre os trabalhadores de doenças ocupacionais causadas por suas condições de trabalho; a proteção dos trabalhadores em seus labores, dos riscos resultantes de fatores adversos à saúde; a colocação e conservação dos trabalhadores nos ambientes ocupacionais adaptados a suas aptidões fisiológicas e psicológicas. (DeCS, 2017)

Segundo Silva,(2016) se verificado as estatísticas da Organização Mundial de Saúde (OMS) e das estatísticas do Ministério da Previdência Social (MPS) pode ser observado que $40 \%$ dos trabalhadores podem ser atingidos por transtornos mentais e que os afastamentos por devido a problemas na saúde mental é a terceira maior causa de afastamento laboral no país, o que demonstra a importância em compreender o fator de trabalho no desgaste mental do trabalhador, o autor salienta a importância de se perceber que o causador da doença do desgaste mental não é uma problema individual e sim social, pois precisa-se considerar que os mesmos sofrem "pressões, exigências, prazos e outras formalidades" do decorrer de seu labor.

Segundo Araujo, (2017), o trabalho pode ser um agente produtor do equilíbrio ou de fadiga, dependendo de como os desejos se demonstram, sendo eles prazerosos ou não e por este motivo se faz fundamental entender a relação entre trabalho e trabalhador para se construir estratégias em busca de um ambiente laboral saudável. 
Os elementos do trabalho interagem dinamicamente entre si e com o trabalhador, o forçando a um processo de adaptação aos processos e cargas de trabalho enfrentados que se convertem em desgaste e, por conseguinte, repercutem em sua capacidade corporal e psíquica (Araujo, 2017, p.3242).

Para Araujo (2017),o trabalho vem sendo gradativamente observado como fator decisivo no processo saúde e doença, porem por ser a saúde mental algo de difícil mensuração o seu reconhecimento está sendo feito a passos lentos pela Vigilância em Saúde do trabalhador, VISAT, o Centros de Referências Especializados em Saúde do Trabalhador, CEREST, vem sendo mais observado pelos trabalhadores como um ambiente de busca pela saúde física do trabalhador em relação ao trabalho do que pela saúde mental, até por que a uma dificuldade em os próprios trabalhadores reconhecerem os problemas relacionados a saúde mental.

Araujo (2017) nos traz a observação de que os trabalhadores poderiam se manifestar em prol de condições de trabalho adequadas a sua realidade, porém o trabalho é utilizado como fator de dominação devido ao medo de perder o emprego o que faz os empregados se sentirem inseguros e descartáveis causando isolamento entre funcionários, perda da solidariedade e a concorrência entre os mesmos. O trabalhador precisa revigorar suas energias com repousos regulares, afinal o ser humano possui limites fisiológicos e trabalhos com longas jornadas "pode causar fadiga somática" interferindo na saúde física e psicológica como o esgotamento psíquico ou profissional como a síndrome de burnout, uma doença ocupacional de origem psicológica (Coimbra,2016), descrito e estudado cientificamente pela primeira vez pelo psicólogo Herbert Freundeberg em 1970, tem como significado o estado de esgotamento associado a frustrações com o trabalho, é uma "reação negativa ao estresse crônico no trabalho" gerando sintomas como o distanciamento, irritabilidade, sentimento de ineficiência, baixa realização, baixa energia (Vieira, 2010), interferindo de forma negativa na vida pessoal e social, na saúde e na família do trabalhador (Coimbra,2016).

O tempo o qual o trabalhador não está destinando ao trabalho ele estará destinando a outros fatores essenciais para a comunidade, exercendo atividades sociais na qual se inclui sua família, atividades recreativas, físicas e culturais. Uma pessoa que descansa de maneira adequada tem maior rendimento e maior qualidade em seu serviço, já uma pessoa com fadiga física e psicológica pode aumentar os acidentes de trabalho e doenças advindas do mesmo, "colocando a saúde, a segurança e a vida do trabalhador em risco, aumentando os 
riscos da infortunística do trabalho e dos custos à título de reparação dos danos decorrentes de acidentes do trabalho e doenças ocupacionais"(Coimbra, 2016).

\section{Metodologia}

O estudo propõe uma revisão sistemática da literatura dos últimos seis anos, mais especificamente de 2014 a 2020 . Similar a uma investigação, a Revisão Sistemática da Literatura é uma pesquisa que faz um resumo do tema escolhido, sendo importante para unir informações que encontram-se em estudos que se encontram separados o que poderá influenciar em futuras pesquisas (Sampaio, Mancini, 2007),

Para Galvão e Perreira,(2014) a metodologia segue a partir de uma sequencia de informações estabelecidas na seguinte ordem, primeiro elaboração da pergunta de pesquisa; em seguida a busca na literatura; em sequência a seleção dos artigos; extração dos dados; avaliação da qualidade metodológica; síntese dos dados; avaliação da qualidade das evidências; e por último a redação e publicação dos resultados.

O presente estudo tem como pergunta de partida: Qual a importância do repouso laboral para a saúde mental do trabalhador?

Para embasar o estudo, foram utilizados materiais que tratam da psicologia organizacional e saúde do trabalhador, legislação trabalhista e saúde mental. Inicialmente os artigos foram selecionados pelos títulos e resumos que contivessem algum dos descritores: jornada de trabalho, descanso, carga horária, qualidade de vida, saúde do trabalhador, legislação trabalhista, a escolha dos bancos de dados eletrônicos ocorreu tendo em vista que são os mais conhecidos e acessados no Brasil. As fontes de pesquisa utilizadas foram: Scielo e PePSIC.

A base de dados SciELO - Scientific Eletronic Library Online, foi a primeiro a ser utilizada, a mesma foi elaborada pela Fundação de Amparo à Pesquisa, é virtual e atua com o Centro Latino Americano e do Caribe de Informações em Ciências da Saúde. (SciELO, 2016).

O PePSIC - Portal Periódicos Eletrônicos de Psicologia, foi a segunda fonte de pesquisa virtual da União Latino-Americana de Entidades de Psicologia que tem como proposito dar maior evidencia ao conhecimento psicológico e científico gerado nos países latino Americanos (PePSIC, 2016). 
Esta revisão foi produzida através de uma triagem de artigos na qual foram selecionados os que tinham em sua base de dados informações sobre os descritores, utilizando-se de leitura flutuante.

A analise dos dados toma como base a Analise de conteúdo de Bardin (1997), que diz que a analise de dados são um conjunto de instrumentos metodológicos que se utiliza de uma hermenêutica controlada que se baseia na dedução, no qual temos que interpretar o não dito, se fazendo observações cuidadosas, porém sustidas de técnicas de validação, instrumentos esses adaptáveis ao campo escolhido de forma a fazer uma descrição analítica, analisando o significado e o significante do conteúdo.

No presente estudo, a análise dos conteúdos foi realizada após a escolha dos artigos pelos títulos e resumos, servindo como maneira de avaliar os artigos secundariamente.

Os critérios de inclusão utilizados nesta pesquisa foram na seguinte sequência: Artigos publicados nos últimos anos, especificamente de 2007 a 2020; Artigos completos e originais; em idioma português; estudos transversais, pesquisas de campo exploratória; artigos que apresentavam alguma das palavras chaves no resumo ou título.

Os critérios de exclusão foram: artigos que não contemplavam o assunto abordado no presente trabalho; em idiomas que não fosse português ; materiais publicados antes de 2007.

Foram encontrados 162 artigos, dos quais 16 foram selecionados para constituir a presente pesquisa, conforme o fluxograma a seguir:

Figura 1- fluxograma ilustrativo para realização da seleção dos artigos

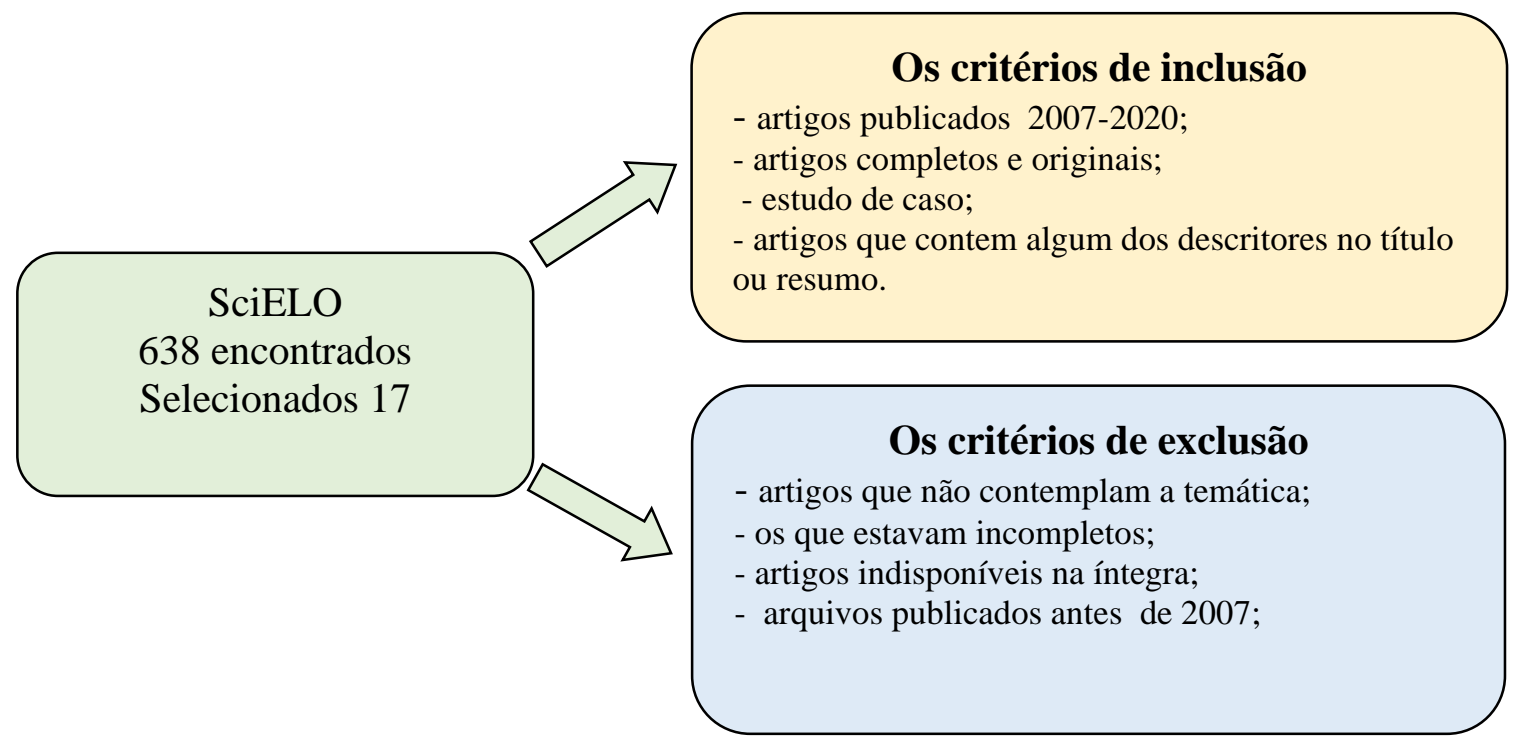

Fonte: Dados da Pesquisa, 2020. 
Figura 2- Fluxograma ilustrativo para realização da seleção dos artigos

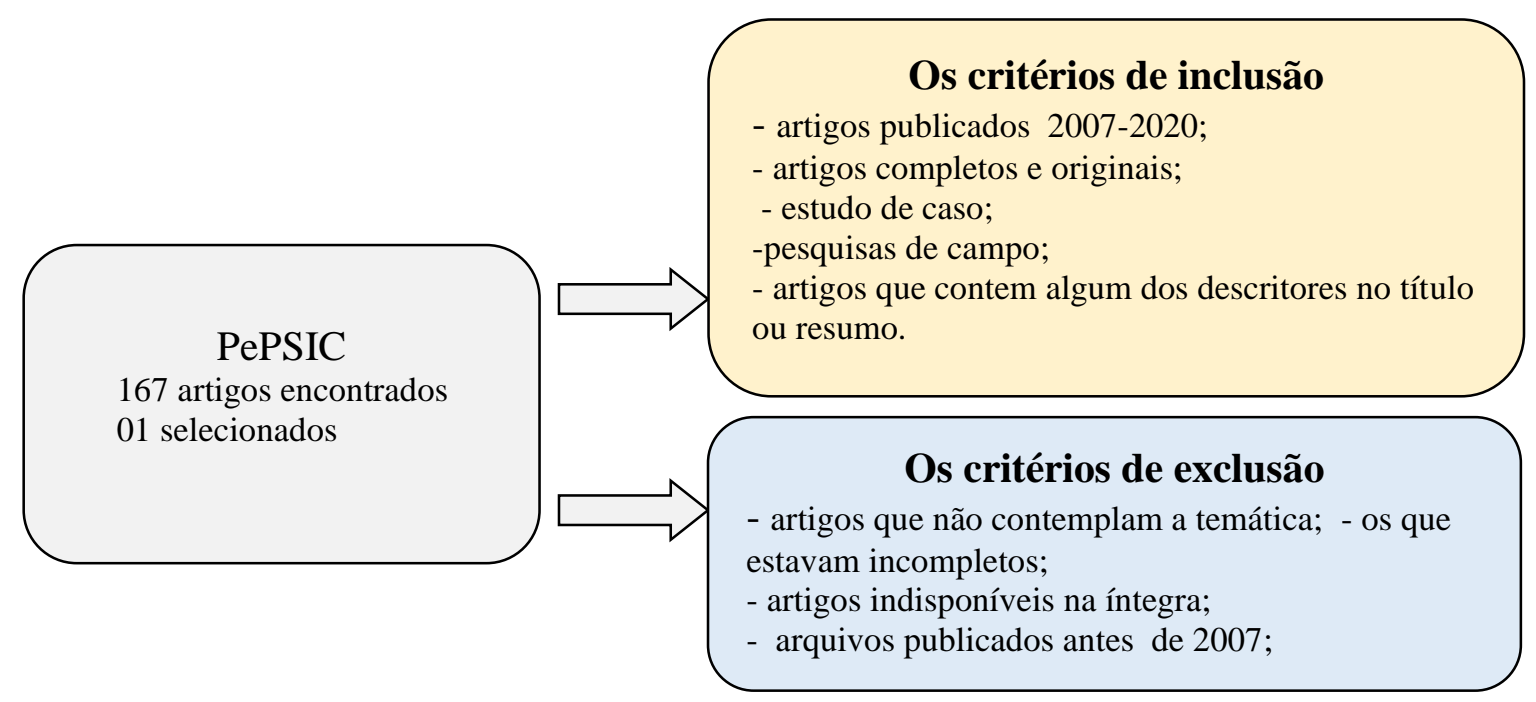

Fonte: Dados da Pesquisa, 2020.

Na tabela 1 exposta abaixo, consta a lista dos 18 artigos que foram selecionados para a presente pesquisa a partir da escolha através dos critérios de inclusão e exclusão, sendo dispostos de acordo com o ano de publicação, dos mais recentes aos mais antigos.

Tabela 1 - artigos selecionados para esse estudo.

\begin{tabular}{l|l}
\hline Autor(es) & Ano \\
\hline ARAUJO; PALMA & 2017 \\
\hline BELLINTANI & 2019 \\
\hline CARNEIRO; FERREIRA & 2007 \\
\hline COIMBRA & 2016 \\
\hline COSTA & 2020 \\
\hline CUNHA & 2020 \\
\hline GAINO & 2018 \\
\hline GALVAO; PEREIRA & 2014 \\
\hline GAMA; CAMPOS, & 2014 \\
\hline MACHADO & 2018 \\
\hline PINA; STOTZ, & 2015 \\
\hline SAMPAIO, RF; MANCINI, MC & 2007 \\
\hline SANTOS & 2017 \\
\hline SILVA; BERNARDO; SOUZA & 2016 \\
\hline SILVA-JUNIOR; FISCHER & 2015 \\
\hline VIEIRA & 2010 \\
\hline
\end{tabular}

Fonte: Dados da Pesquisa, 2020. 


\section{Resultados e Discussão}

Foram selecionados 16 artigos datados no intervalo de 2007-2020, dos quais dois foram publicados no ano de 2007, um no ano de 2010, dois em 2014, dois em 2015, dois em 2016, três em 2017, dois em 2018, um em 2019 dois em 2020. Sendo possível observar que o ano de 2017 teve um maior número de publicações em relação aos demais que têm basicamente a mesma quantidade de publicações. Segue as informações no gráfico a seguir:

Gráfico 1- Imagem ilustrativa da seleção dos artigos.

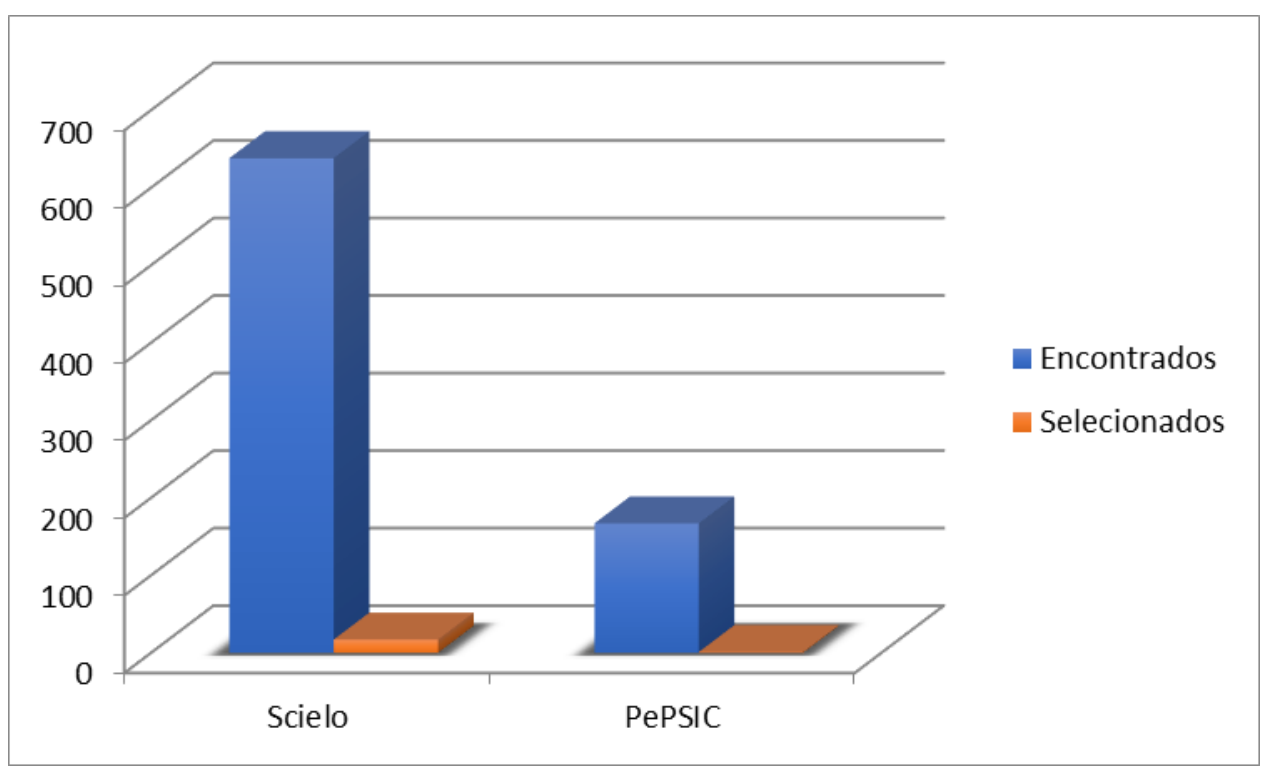

Fonte: Dados da Pesquisa, 2020.

Ao observarmos o gráfico podemos perceber que a quantidade de artigos que tem alguma relação com o tema é significativa, mas quando fazemos um filtro dos critérios de inclusão e exclusão, passamos a observar que o tema é pouco abordado de forma especifica ou mais clara em relação ao descanso de interjornada e intrajornada para a saúde mental do trabalhador.

Em relação aos autores, podemos perceber que uma variação entre as quantidades de autores, sendo mais frequente os artigos com um, dois, três ou quatro autores, e não foi percebido trabalhos com com mais autores.

Os artigos selecionados foram divididos em 3 categorias tendo como assunto os seguintes temas: 1) Saúde do trabalhador (7 artigos) ; 2) Jornada de trabalho (4 artigos) e; 3 ) Afastamento do trabalho ( 3 artigos ). Vejamos a tabela 3, 4 e 5 a seguir. 


\section{Categoria 1 - Saúde do trabalhador}

Tabela 3: Informações das categorias de saúde do trabalhador selecionados.

\begin{tabular}{|c|c|c|c|c|}
\hline \multicolumn{5}{|c|}{ CATEGORIAS DOS ARTIGOS SELECIONADOS } \\
\hline AUTOR/ TEMA & $\begin{array}{c}\text { PERIÓDICO/ } \\
\text { ANO }\end{array}$ & $\begin{array}{l}\text { TIPO DE } \\
\text { ESTUDO }\end{array}$ & AMOSTRA & $\begin{array}{l}\text { OBJETIVOS E } \\
\text { RESULTADOS }\end{array}$ \\
\hline $\begin{array}{l}\text { SILVA, Mariana Pereira } \\
\text { da; BERNARDO, } \\
\text { Marcia Hespanhol; } \\
\text { SOUZA, Heloísa } \\
\text { Aparecida. . } \\
\text { Relação entre saúde } \\
\text { mental e trabalho: a } \\
\text { concepção de } \\
\text { sindicalistas e possíveis } \\
\text { formas de enfrentamento }\end{array}$ & $\begin{array}{l}\text { SciELO } \\
\text { Rev. bras. saúde } \\
\text { ocup., São Paulo } \\
\text {, v. 41, e23, } \\
2016 \text {. }\end{array}$ & $\begin{array}{l}\text { A pesquisa teve } \\
\text { caráter } \\
\text { qualitativo e as } \\
\text { informações } \\
\text { foram obtidas } \\
\text { por meio de } \\
\text { entrevistas } \\
\text { reflexivas em } \\
\text { profundidade, } \\
\text { como propõe } \\
\text { Hammersley e } \\
\text { Atkinson. Os } \\
\text { entrevistados } \\
\text { foram } \\
\text { incentivados a } \\
\text { falarem } \\
\text { livremente, } \\
\text { favorecendo, } \\
\text { assim, a } \\
\text { compreensão de } \\
\text { suas concepções } \\
\text { a respeito da } \\
\text { SMRT e das } \\
\text { ações realizadas } \\
\text { ou que } \\
\text { poderiam ser } \\
\text { empreendidas } \\
\text { pelos seus } \\
\text { respectivos } \\
\text { sindicatos sobre } \\
\text { questões } \\
\text { relativas a esse } \\
\text { tema. }\end{array}$ & $\begin{array}{l}\text { A coleta foi feita } \\
\text { com } 5 \\
\text { representantes } \\
\text { sindicais. }\end{array}$ & $\begin{array}{l}\text { objetivo compreender } \\
\text { as concepções de } \\
\text { sindicalistas sobre a } \\
\text { relação entre saúde } \\
\text { mental e trabalho. Os } \\
\text { resultados desse } \\
\text { estudo mostraram que, } \\
\text { no contexto geral, } \\
\text { apesar do tema da } \\
\text { SMRT ser } \\
\text { negligenciado em } \\
\text { muitos sindicatos, } \\
\text { conforme diversos } \\
\text { estudos indicam4-7, } \\
\text { existem sindicalistas } \\
\text { sensíveis e } \\
\text { comprometidos com a } \\
\text { temática. Desse modo, } \\
\text { busca-se, neste artigo, } \\
\text { apresentar as } \\
\text { concepções desses } \\
\text { sindicalistas, bem } \\
\text { como algumas de suas } \\
\text { ações que podem } \\
\text { indicar rumos para } \\
\text { abordagens do } \\
\text { movimento sindical } \\
\text { que favoreçam o } \\
\text { enfrentamento do } \\
\text { adoecimento mental } \\
\text { relacionado ao } \\
\text { trabalho. }\end{array}$ \\
\hline $\begin{array}{l}\text { ARAUJO, Tania Maria } \\
\text { de; PALMA, Tarciso de } \\
\text { Figueiredo; ARAUJO, } \\
\text { Natália do Carmo. } \\
\text { Vigilância em Saúde } \\
\text { Mental e Trabalho no } \\
\text { Brasil: características, } \\
\text { dificuldades e desafios. }\end{array}$ & $\begin{array}{l}\text { SciELO } \\
\text { Ciênc. saúde } \\
\text { coletiva, Rio de } \\
\text { Janeiro, v. } 22, \mathrm{n} \text {. } \\
\text { 10, p. } 3235-3246 \text {, } \\
\text { Oct. } 2017 .\end{array}$ & $\begin{array}{l}\text { Foi realizada } \\
\text { revisão de } \\
\text { literatura de } \\
\text { publicações } \\
\text { nacionais, } \\
\text { atendendo ao } \\
\text { objetivo de } \\
\text { verificar as } \\
\text { produções } \\
\text { brasileiras e } \\
\text { fomentar } \\
\text { reflexões sobre } \\
\text { a temática de } \\
\text { Visat em Saúde } \\
\text { Mental. }\end{array}$ & $\begin{array}{l}\text { A coleta foi feita } \\
\text { com analise de } 14 \\
\text { textos. }\end{array}$ & $\begin{array}{l}\text { Verificar as produções } \\
\text { brasileiras e fomentar } \\
\text { reflexões sobre a } \\
\text { temática de Visat em } \\
\text { Saúde Mental. Foram } \\
\text { consultadas as bases } \\
\text { de dados virtuais: } \\
\text { Google Scholar, } \\
\text { SciELO, Lilacs e } \\
\text { PubMed, utilizando os } \\
\text { seguintes descritores: } \\
\text { saúde do trabalhador, } \\
\text { saúde mental, } \\
\text { trabalhadores, saúde } \\
\text { mental e trabalho e } \\
\text { Vigilância em Saúde, } \\
\text { indexados na base de } \\
\text { dados Descritores em } \\
\text { Ciências da Saúde }\end{array}$ \\
\hline
\end{tabular}




\begin{tabular}{|c|c|c|c|c|}
\hline & & & & $\begin{array}{l}\text { (DeCS). } \\
\text { Os resultados foram } \\
\text { categorizados de } \\
\text { acordo com o } \\
\text { conhecimento prévio } \\
\text { sobre o tema e suas } \\
\text { lacunas e por repetição } \\
\text { no conteúdo dos } \\
\text { mesmos. }\end{array}$ \\
\hline $\begin{array}{l}\text { GAINO, Loraine Vivian } \\
\text { et al . } \\
\text { O conceito de saúde } \\
\text { mental para profissionais } \\
\text { de saúde: um estudo } \\
\text { transversal e } \\
\text { qualitativo*. }\end{array}$ & $\begin{array}{l}\text { PePSIC } \\
\text { SMAD, Rev. } \\
\text { Eletrônica Saúde } \\
\text { Mental Álcool } \\
\text { Drog. (Ed. } \\
\text { port.), Ribeirão } \\
\text { Preto, v. 14, n. } \\
\text { 2, p. 108-116, } \\
\text { 2018. }\end{array}$ & $\begin{array}{l}\text { trata-se de um } \\
\text { estudo } \\
\text { qualitativo, } \\
\text { realizado no ano } \\
\text { de } 2017 .\end{array}$ & $\begin{array}{l}\text { A coleta de dados } \\
\text { foi realizada por } \\
\text { meio de } \\
\text { entrevistas } \\
\text { semiestruturadas } \\
\text { com } 20 \\
\text { profissionais dos } \\
\text { referidos serviços } \\
\text { de uma cidade do } \\
\text { interior do estado } \\
\text { de São Paulo. }\end{array}$ & $\begin{array}{l}\text { Este estudo objetivou } \\
\text { investigar e comparar } \\
\text { o conceito de saúde } \\
\text { mental para } \\
\text { profissionais atuantes } \\
\text { em diferentes serviços } \\
\text { da rede de saúde } \\
\text { pública } \\
\text { No entanto, a maioria } \\
\text { dos participantes } \\
\text { associou tal conceito } \\
\text { com a noção de bem- } \\
\text { estar, integralidade do } \\
\text { ser humano e } \\
\text { determinação social } \\
\text { do processo saúde- } \\
\text { doença. }\end{array}$ \\
\hline $\begin{array}{l}\text { GAMA, Carlos Alberto } \\
\text { Pegolo da; CAMPOS, } \\
\text { Rosana Teresa Onocko; } \\
\text { FERRER, Ana Luiza. } \\
\text { Saúde mental e } \\
\text { vulnerabilidade social: a } \\
\text { direção do tratamento. }\end{array}$ & $\begin{array}{l}\text { SciELO } \\
\text { Rev. latinoam. } \\
\text { psicopatol. } \\
\text { fundam., São } \\
\text { Paulo, v. 17, n. } \\
\text { 1, p. 69-84, Mar. } \\
2014 \text {. }\end{array}$ & $\begin{array}{l}\text { Pesquisa de } \\
\text { caráter } \\
\text { Reflexivo. }\end{array}$ & $\begin{array}{l}\text { A coleta de dados } \\
\text { foi feita através de } \\
29 \text { artigos } \\
\text { cientificos }\end{array}$ & $\begin{array}{l}\text { O objetivo do texto é } \\
\text { refletir sobre as } \\
\text { relações entre saúde } \\
\text { mental e } \\
\text { vulnerabilidade social } \\
\text { a partir do encontro da } \\
\text { Psiquiatria Biológica } \\
\text { com a Reforma } \\
\text { Psiquiátrica. } \\
\text { Problematizamos o } \\
\text { conceito de saúde } \\
\text { mental, o conceito de } \\
\text { vulnerabilidade social, } \\
\text { os manuais } \\
\text { diagnósticos, as } \\
\text { pesquisas } \\
\text { epidemiológicas, } \\
\text { tendo como pano de } \\
\text { fundo as Políticas } \\
\text { Públicas de Saúde. } \\
\text { Identificamos a } \\
\text { necessidade de } \\
\text { superação da lógica } \\
\text { técnico-científico } \\
\text { tradicional } \\
\text { incorporando a } \\
\text { singularidade e } \\
\text { saberes ligados aos } \\
\text { sujeitos que são } \\
\text { afetados pelo } \\
\text { sofrimento. }\end{array}$ \\
\hline
\end{tabular}




\begin{tabular}{|c|c|c|c|c|}
\hline $\begin{array}{l}\text { COSTA, Zilma Maria } \\
\text { Severino Silva e et al . } \\
\text { Validação brasileira dos } \\
\text { bancos de itens Distúrbio } \\
\text { do Sono e Distúrbio da } \\
\text { Vigília do Patient- } \\
\text { Reported Outcomes } \\
\text { Measurement } \\
\text { Information System } \\
\text { (PROMIS). }\end{array}$ & $\begin{array}{l}\text { SciELO } \\
\text { Cad. Saúde } \\
\text { Pública, Rio de } \\
\text { Janeiro, v. 36, n. } \\
\text { 6, e00228519, } \\
2020 \text {. }\end{array}$ & & $\begin{array}{l}\text { A amostra } \\
\text { constituída por } \\
627 \text { participantes } \\
\text { com mais de } 18 \\
\text { anos. }\end{array}$ & $\begin{array}{l}\text { O objetivo deste } \\
\text { estudo foi validar a } \\
\text { versão brasileira dos } \\
\text { bancos de itens } \\
\text { Distúrbio do Sono e } \\
\text { Distúrbio da Vigília } \\
\text { do Patient-Reported } \\
\text { Outcomes } \\
\text { Measurement } \\
\text { Information } \\
\text { System (PROMIS). A } \\
\text { validação desses } \\
\text { bancos de itens foi } \\
\text { feita por meio da } \\
\text { Teoria Clássica dos } \\
\text { Testes, Teoria de } \\
\text { Resposta ao Item, } \\
\text { calibração dos itens } \\
\text { conforme o modelo de } \\
\text { resposta gradual } \\
\text { proposto por } \\
\text { Samejima e análise do } \\
\text { Funcionamento } \\
\text { Diferencial do Item } \\
\text { (DIF), }\end{array}$ \\
\hline $\begin{array}{l}\text { CUNHA, Cláudio L. } \\
\text { Pereira da } \\
\text {. Influência da Atividade } \\
\text { Física na Hipertensão } \\
\text { Arterial em } \\
\text { Trabalhadores. }\end{array}$ & $\begin{array}{l}\text { SciELO } \\
\\
\text {. Arq. Bras. } \\
\text { Cardiol., São } \\
\text { Paulo, v. 114, n. } \\
\text { 5, p. 762-763, } \\
\text { May 2020. }\end{array}$ & $\begin{array}{l}\text { Minieditorial } \\
\text { referente ao } \\
\text { artigo: } \\
\text { Hipertensão } \\
\text { Arterial em } \\
\text { Trabalhadores: } \\
\text { O Efeito } \\
\text { Cumulativo das } \\
\text { Dimensões da } \\
\text { Atividade Física } \\
\text { sobre esse } \\
\text { Agravo. }\end{array}$ & $\begin{array}{l}\text { A amostra foi de } \\
1.070 \\
\text { participantes } \\
\text { vinculados a } 2 \\
\text { empresas com } \\
\text { características de } \\
\text { exigência física } \\
\text { bem distintas: } 624 \\
\text { trabalhadores em } \\
\text { limpeza urbana e } \\
446 \text { em indústria } \\
\text { de calçados. }\end{array}$ & $\begin{array}{l}\text { A Atividade Física é } \\
\text { benéfica à saúde e } \\
\text { ajuda a controlar a } \\
\text { Pressão Arterial, } \\
\text { principalmente com a } \\
\text { prática de exercícios } \\
\text { aeróbicos, mas } \\
\text { também com os } \\
\text { exercícios resistivos. } \\
\text { O efeito cumulativo de } \\
\text { diferentes } \\
\text { modalidades da AF, } \\
\text { como estudado por } \\
\text { Ribeiro Jr. \& } \\
\text { Fernandes,10 } \\
\text { contribui para a } \\
\text { proteção à HA. A } \\
\text { AFO deve ser avaliada } \\
\text { com cautela e } \\
\text { profundidade, de } \\
\text { maneira a se encontrar } \\
\text { situações ótimas das } \\
\text { atividades físicas, de } \\
\text { forma a utilizá-la em } \\
\text { benefício da saúde, e } \\
\text { não como um } \\
\text { mecanismo deletério } \\
\text { para o trabalhador. }\end{array}$ \\
\hline $\begin{array}{l}\text { PINA, José Augusto; } \\
\text { STOTZ, Eduardo } \\
\text { Navarro. } \\
\text { Intensificação do }\end{array}$ & $\begin{array}{l}\text { Saude soc., São } \\
\text { Paulo, v. } 24 \text {, n. }\end{array}$ & Estudo & $\begin{array}{l}7 \text { visitas à fábrica } \\
\text { e vinte e nove } \\
\text { entrevistas: vinte e } \\
\text { duas com } \\
\text { trabalhadores }\end{array}$ & $\begin{array}{l}\text { Neste estudo, } \\
\text { apreendemos o } \\
\text { processo de } \\
\text { intensificação do } \\
\text { trabalho e saúde, a }\end{array}$ \\
\hline
\end{tabular}




\begin{tabular}{|l|l|l|l|l|}
\hline $\begin{array}{l}\text { trabalho e saúde dos } \\
\text { trabalhadores: um estudo } \\
\text { na Mercedes Benz do } \\
\text { Brasil, São Bernardo do } \\
\text { Campo, São Paulo }\end{array}$ & $\begin{array}{l}\text { 3, p. 826-840, } \\
\text { Sept. 2015. }\end{array}$ & & $\begin{array}{l}\text { diretos e sete com } \\
\text { representantes } \\
\text { sindicais. }\end{array}$ & $\begin{array}{l}\text { partir das maneiras } \\
\text { como os operários da } \\
\text { empresa o } \\
\text { experimentam, } \\
\text { especialmente ao } \\
\text { assinalar como as } \\
\text { práticas de exploração } \\
\text { e expropriação, ritmo } \\
\text { de trabalho, } \\
\text { prolongamento do } \\
\text { trabalho e } \\
\text { administração por } \\
\text { estresse confrontam a } \\
\text { capacidade coletiva do } \\
\text { trabalhador. }\end{array}$ \\
\hline
\end{tabular}

Fonte: Dados da Pesquisa, 2020.

Araujo; Palma; Araujo,( 2017), fazem a reflexão sobre a forma capitalista do processo de trabalho que pode vir a acarretar um trabalho precarizado e adoecedor, o desenvolvimento do trabalho possui uma dinâmica de relações entre o homem e o seu entorno. O trabalho é a fonte de realizações de objetivos concretos, como a manutenção da saúde, moradia, alimentação entre outros, mas além de realizações concretas existe a realização abstrata na qual o funcionário sente-se bem em fazer a sua função, na qual ele percebe um valos sentimental em sua função, o trabalha é mais que mercadoria, ou troca de serviço por dinheiro, é movimentar-se em prol de algo mais importante, de algo que faça sentido para o trabalhador. Analisando os resultados identificados nos artigos percebe-se que negligenciado em muitos sindicatos, conforme identificado gerando em sua maioria lacunas dos estudos em ações eficientes e eficazes para garantir o bem-estar, integralidade do ser humano, apontando o estresse como sendo fator resultante dessa carga-horária extensiva comprometendo a saúde do trabalhador.

\section{Categoria 2- Jornada de trabalho.}

Tabela 4: Informações das categorias de Jornada de trabalho selecionadas.

\begin{tabular}{|l|l|l|l|l|}
\hline \multicolumn{5}{|c|}{ CATEGORIAS DOS ARTIGOS SELECIONADOS } \\
\hline AUTOR/TEMA & PERIÓDICO/ANO & $\begin{array}{l}\text { TIPO DE } \\
\text { ESTUDO }\end{array}$ & AMOSTRA & $\begin{array}{l}\text { OBJETIVOS E } \\
\text { RESULTADOS }\end{array}$ \\
\hline $\begin{array}{l}\text { MACHADO, } \\
\text { Alisson Diego. }\end{array}$ & SciELO & Comentário & $\begin{array}{l}\text { A coleta de dados } \\
\text { foi feita através de } \\
11 \text { artigos }\end{array}$ & \\
$\begin{array}{l}\text { Implicações da } \\
\text { reforma trabalhista } \\
\text { na alimentação dos } \\
\text { trabalhadores. }\end{array}$ & $\begin{array}{l}\text { Janeiro, v. 28, n. 2, } \\
\text { e280203, 2018 }\end{array}$ & & & $\begin{array}{l}\text { Entrevistas } \\
\text { semi- }\end{array}$ \\
\hline CARNEIRO, Thiago & SciELO & $\begin{array}{l}\text { A amostra } \\
\text { utilizada foi 53 }\end{array}$ & $\begin{array}{l}\text { O objetivo deste estudo } \\
\text { foi identificar os possíveis }\end{array}$ \\
\hline
\end{tabular}




\begin{tabular}{|c|c|c|c|c|}
\hline $\begin{array}{l}\text { Lopes; FERREIRA, } \\
\text { Mário César. } \\
\text { Redução de jornada } \\
\text { melhora a qualidade } \\
\text { de vida no trabalho?: } \\
\text { A experiência de } \\
\text { uma organização } \\
\text { pública. }\end{array}$ & $\begin{array}{l}\text { brasileira. Rev. } \\
\text { Psicol., Organ. } \\
\text { Trab., Florianópolis } \\
\text {, v. 7, n. 1, p. 131- } \\
\text { 157, jun. } 2007\end{array}$ & $\begin{array}{l}\text { estruturadas, } \\
\text { elaboradas com } \\
\text { base nos } \\
\text { resultados da } \\
\text { análise } \\
\text { documental das } \\
\text { escalas e } \\
\text { acrescidas de } \\
\text { questões } \\
\text { referentes às } \\
\text { mudanças } \\
\text { decorrentes da } \\
\text { redução de } \\
\text { jornada. }\end{array}$ & & $\begin{array}{l}\text { impactos da redução de } \\
\text { jornada de trabalho para a } \\
\text { Qualidade de Vida no } \\
\text { Trabalho (QVT) de } \\
\text { empregados em um } \\
\text { departamento de uma } \\
\text { organização pública } \\
\text { brasileira. A literatura } \\
\text { aponta uma estreita } \\
\text { relação entre jornada e } \\
\text { QVT, especialmente } \\
\text { quanto à compatibilização } \\
\text { da vida pessoal com o } \\
\text { trabalho e o } \\
\text { aproveitamento do tempo } \\
\text { no trabalho. }\end{array}$ \\
\hline $\begin{array}{l}\text { COIMBRA, } \\
\text { Rodrigo. } \\
\text { Fundamentos e } \\
\text { evolução da } \\
\text { limitação } \\
\text { constitucional da } \\
\text { duração do tempo de } \\
\text { trabalho no brasil. }\end{array}$ & $\begin{array}{l}\text { SciELO } \\
\text { e-Pública, Lisboa, } \\
\text { v. } 3 \text {, n. 1, p. 184-206, } \\
\text { abr. } 2016 \text {. }\end{array}$ & Documental & 47 artigos & $\begin{array}{l}\text { A duração do trabalho foi } \\
\text { e continua sendo um dos } \\
\text { temas mais importantes } \\
\text { do Direito do Trabalho, } \\
\text { pois a necessidade de se } \\
\text { estabelecer limites } \\
\text { imperativos ao tempo } \\
\text { dedicado ao trabalho } \\
\text { (diário, semanal, mensal e } \\
\text { anual) segue sendo uma } \\
\text { complexa e difícil } \\
\text { questão, haja vista sua } \\
\text { dinâmica e a constante } \\
\text { modificação nas formas } \\
\text { de trabalho notadamente } \\
\text { num contexto de } \\
\text { globalização da economia } \\
\text { e da chamada revolução } \\
\text { tecnológica. }\end{array}$ \\
\hline
\end{tabular}

Fonte: Dados da Pesquisa, 2020.

A alteração na jornada de trabalho foi um tema bastente debatido, pois o mesmo reflete em como os demais aspectos da vida do trabalhador irá ser administrado, se tornando um tema constante entre empregado e empregador, é importante salientar que a organização precisa se harmonizar com o bem estar do trabalhador (CARNEIRO; FERREIRA, 2020).

Percebe-se que como direito do trabalhador, pois a necessidade de se estabelecer limites imperativos ao tempo dedicado ao trabalho garante a preservação do bem-estar e qualidade de vida do trabalhador . 


\section{Categoria 3- Afastamento do trabalho}

Tabela 5: Informações das categorias de Afastamento do trabalho.

\begin{tabular}{|c|c|c|c|c|}
\hline \multicolumn{5}{|c|}{ CATEGORIAS DOS ARTIGOS SELECIONADOS } \\
\hline AUTOR/TEMA & PERIÓDICO/ANO & TIPO DE ESTUDO & AMOSTRA & $\begin{array}{l}\text { OBJETIVOS E } \\
\text { RESULTADOS }\end{array}$ \\
\hline $\begin{array}{l}\text { SANTOS, Sérgio } \\
\text { Valverde } \\
\text { Marques dos et } \\
\text { al. } \\
\text { Acidente de } \\
\text { trabalho e } \\
\text { autoestima de } \\
\text { profissionais de } \\
\text { enfermagem em } \\
\text { ambientes } \\
\text { hospitalares. }\end{array}$ & $\begin{array}{l}\text { SciELO } \\
\text { Rev. Latino-Am. } \\
\text { Enfermagem, Ribeirão } \\
\text { Preto, v. } 25 \text {, e2872, } \\
2017 \text {. }\end{array}$ & $\begin{array}{l}\text { Estudo descritivo- } \\
\text { analítico, transversal, } \\
\text { de abordagem } \\
\text { quantitativa }\end{array}$ & $\begin{array}{l}\text { Desenvolvido } \\
\text { em três } \\
\text { instituições } \\
\text { hospitalares: } \\
\text { uma privada de } \\
\text { médio porte } \\
\text { (Instituição A, } \\
\text { com } 289 \\
\text { profissionais), } \\
\text { uma filantrópica } \\
\text { de médio porte } \\
\text { (Instituição B, } \\
\text { com } 181 \\
\text { profissionais) e } \\
\text { a outra privada } \\
\text { de pequeno } \\
\text { porte }\end{array}$ & 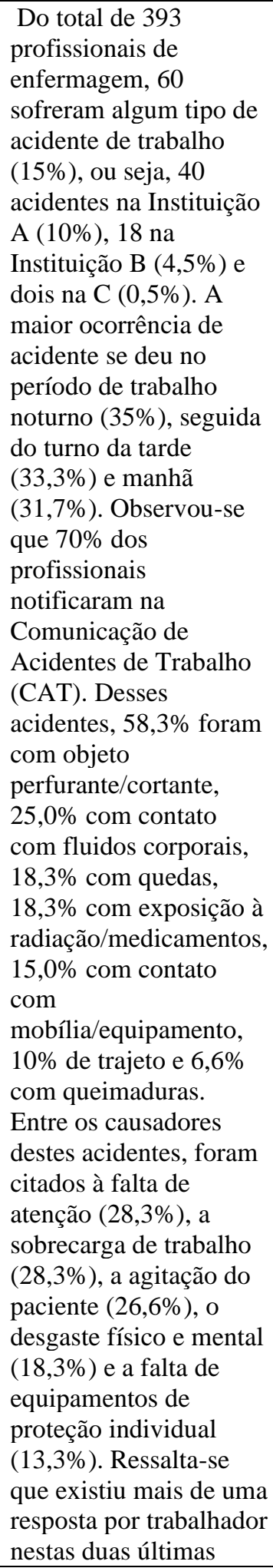 \\
\hline
\end{tabular}




\begin{tabular}{|c|c|c|c|c|}
\hline & & & & variáveis. \\
\hline $\begin{array}{l}\text { SILVA- } \\
\text { JUNIOR, João } \\
\text { Silvestre; } \\
\text { FISCHER, Frida } \\
\text { Marina. } \\
\text { Afastamento do } \\
\text { trabalho por } \\
\text { transtornos } \\
\text { mentais e } \\
\text { estressores } \\
\text { psicossociais } \\
\text { ocupacionais }\end{array}$ & $\begin{array}{l}\text { SciELO } \\
\text { Rev. bras. epidemiol., } \\
\text { São Paulo, v. } 18, \text { n. 4, p. } \\
\text { 735-744, Dec. } 2015 \text {. }\end{array}$ & Estudo analítico & $\begin{array}{l}131 \text { requerentes } \\
\text { de auxílio- } \\
\text { doença por } \\
\text { transtornos } \\
\text { mentais. }\end{array}$ & $\begin{array}{l}\text { A concessão do } \\
\text { benefício auxílio- } \\
\text { doença acidentário não } \\
\text { foi associada a } \\
\text { variáveis } \\
\text { sóciodemográficas, } \\
\text { hábitos/estilo de vida } \\
\text { ou fatores psicossociais } \\
\text { no trabalho. A } \\
\text { exposição ocupacional } \\
\text { a estressores } \\
\text { psicossociais esteve } \\
\text { presente no relato da } \\
\text { maioria dos } \\
\text { trabalhadores afastados } \\
\text { do trabalho por } \\
\text { transtornos mentais. } \\
\text { Entretanto, diversos } \\
\text { casos não foram } \\
\text { reconhecidos pela } \\
\text { perícia médica } \\
\text { previdenciária como } \\
\text { relacionados ao } \\
\text { trabalho, o que pode ter } \\
\text { influenciado nos } \\
\text { resultados das } \\
\text { associações. }\end{array}$ \\
\hline $\begin{array}{l}\text { VIEIRA, Isabela. } \\
\text { Conceito(s) de } \\
\text { burnout: } \\
\text { questões atuais } \\
\text { da pesquisa e a } \\
\text { contribuição da } \\
\text { clínica.. }\end{array}$ & $\begin{array}{l}\text { SciELO } \\
\text {. Rev. bras. saúde } \\
\text { ocup., São Paulo, v. } \\
\text { 35, n. 122, p. 269-276, } \\
\text { Dec. } 2010\end{array}$ & Pesquisa empírica & 46 artigos & $\begin{array}{l}\text { detectar problemas no } \\
\text { relacionamento das } \\
\text { pessoas com o trabalho } \\
\text { (não necessariamente } \\
\text { problemas com outras } \\
\text { pessoas no ambiente de } \\
\text { trabalho). As } \\
\text { adaptações ao } \\
\text { instrumento original } \\
\text { consistiram na } \\
\text { renomeação das } \\
\text { dimensões Exaustão } \\
\text { Emocional (para } \\
\text { Exaustão), } \\
\text { Despersonalização } \\
\text { (para } \\
\text { Cinismo/Ceticismo)2 e } \\
\text { baixa Realização } \\
\text { Pessoal }\end{array}$ \\
\hline
\end{tabular}

Fonte: Dados da Pesquisa, 2020.

Foi percebido através do estudo de Silva e Junior (2015), que há uma ligação entre "fatores psicossociais desfavoráveis" e os afastamentos por consequência de transtornos mentais. Um desses transtornos mentais é a Síndrome de Burnout, identificada como um esgotamento físico e mental causado por metas inalcançáveis e geralmente está associado ao ambiente de trabalho.(Vieira, 2010). 
Estudos confirmam que a exaustão emocional, despersonalização cinismo/ceticismo e baixa realização pessoal sendo efeitos impositivos do desrespeito aos direitos do trabalhador enquanto sequelas percebidas como consequências de experiencias de desrespeito aos diretos do sujeito que trabalha.

\section{Considerações Finais}

Este artigo traz uma revisão sistemática sobre a Importância do Repouso Laboral na Manutenção da Saúde Metal do Trabalhador com base em publicação do período de 2007 a 2020 através de uma seleção detalhada. Foram encontrados um número elevado de publicação em cada base de dados, mas a maioria forma excluídas com base no ano de publicação e coerência com o tema do artigo, sendo que somente 805 foram selecionados para leitura, destes somente 18 atenderam a temática abordada.

Através dos artigos analisados podemos observar a importância dos intervalos de interjornada e intrajornada durante o trabalho como fator que influencia a qualidade de vida do trabalhador, estabelecendo fundamentos para a saúde física e mental do trabalhador, podendo ter importante papel na diminuição dos acidentes de trabalho e doenças ocupacionais reduzindo consequentemente os afastamentos.

\section{Referências}

Araujo, Tania Maria de; Palma, Tarciso de Figueiredo; Araujo, Natália do Carmo (2017). Vigilância em Saúde Mental e Trabalho no Brasil: características, dificuldades e desafios. Ciênc. saúde coletiva, Rio de Janeiro, v. 22, n. 10, p. 3235-3246, Oct. Available from $<$ http://www.scielo.br/scielo.php?script=sci_arttext\&pid=S1413-81232017021003235\&lng=en \&nrm=iso . access on 11 May 2020. https://doi.org/10.1590/1413-812320172210.17552017.

Bardin, L. (1997). Análise de Conteúdo. Lisboa: Edições 70.

Bellintani, Nathalia (2019). Intervalo Interjornada: Como Funciona e Alterações com a Reforma. pontotel. Disponível em: < https://www.pontotel.com.br/intervalo-interjornada/>. Acesso em: 01, Julho de 2020.

Carneiro, Thiago Lopes; Ferreira, Mário César (2007). Redução de jornada melhora a qualidade de vida no trabalho?: A experiência de uma organização pública brasileira. Rev. Psicol., Organ. Trab., Florianópolis , v. 7, n. 1, p. 131-157, jun. Disponível em 
<http://pepsic.bvsalud.org/scielo.php?script=sci_arttext\&pid=S1984-66572007000100007\&lng $=$ pt\&nrm=iso $>$. acessos em 07 jun. 2020 .

Coimbra, Rodrigo (2016). Fundamentos e evolução da limitação constitucional da duração do tempo de trabalho no brasil. e-Pública, Lisboa , v. 3, n. 1, p. 184-206, abr. Disponível em $<$ http://www.scielo.mec.pt/scielo.php?script=sci_arttext\&pid=S2183-184X2016000100011 \&lng=pt\&nrm=iso>. acessos em 29 fev. 2020.

Costa, Zilma Maria Severino Silva e et al. (2020). Validação brasileira dos bancos de itens Distúrbio do Sono e Distúrbio da Vigília do Patient-Reported Outcomes Measurement Information System (PROMIS). Cad. Saúde Pública, Rio de Janeiro , v. 36, n. 6, e00228519. Available from <http://www.scielo.br/scielo.php?script=sci_arttext\&pid=S0102311X2020000604 001\&lng=en\&nrm=iso $>$. access on 02 July 2020. Epub June 08, 2020. http://dx.doi.org/10.1590/0102-311x00228519.

Cunha, Cláudio L. Pereira da (2020).. Influência da Atividade Física na Hipertensão Arterial em Trabalhadores. Arq. Bras. Cardiol., São Paulo , v. 114, n. 5, p. 762-763, May. Available from $<$ http://www.scielo.br/scielo.php?script=sci_arttext\&pid=S0066-782X2020000600762\&lng=en\& $\mathrm{nrm}=\mathrm{iso}>$. access on 02 July 2020. Epub June 01, 2020. https://doi.org/10.36660/abc.20200318.

Descritores em Ciências da Saúde: DeCS. *. Ed. Ver. E ampl. São Paulo: BIREME / OPAS / OMS, 2017. Disponível em :http://decs.bvsalud.org. Acesso em 22 de jun.2017.

GAINO, Loraine Vivian et al. (2018). O conceito de saúde mental para profissionais de saúde: um estudo transversal e qualitativo*. SMAD, Rev. Eletrônica Saúde Mental Álcool Drog. (Ed. port.), Ribeirão Preto , v. 14, n. 2, p. 108-116. Disponível em $<$ http://pepsic.bvsalud.org/scielo.php?script=sci_arttext\&pid=S1806-69762018000200007\&lng= pt\&nrm=iso $>$. acessos em 27 jun. 2020.

Galvao, Taís Freire; Pereira, Mauricio Gomes (2014). Systematic reviews of the literature: steps for preparation. Epidemiol. Serv. Saúde, Brasília , v. 23, n. 1, p. 183-184, Mar. Available from <http://scielo.iec.gov.br/scielo.php?script=sci_arttext\&pid=S1679-49742014000100018 \&lng=en\&nrm=iso >. access on 07 June 2020.

Gama, Carlos Alberto Pegolo da; Campos, Rosana Teresa Onocko; Ferrer, Ana Luiza (2014). Saúde mental e vulnerabilidade social: a direção do tratamento. Rev. latinoam. psicopatol. fundam., São Paulo , v. 17, n. 1, p. 69-84, mar. Disponível em $<$ http://www.scielo.br/scielo.php?script=sci_arttext\&pid=S1415-47142014000100006\&lng=pt\& nrm=iso>. acessos em 27 jun. 2020. https://doi.org/10.1590/S1415-47142014000100006.

Machado, Alisson Diego (2018). Implicações da reforma trabalhista na alimentação dos trabalhadores. Physis, Rio de Janeiro , v. 28, n. 2, e280203. Available from $<$ http://www.scielo.br/scielo.php?script=sci_arttext\&pid=S0103-73312018000200300\&lng=en\& nrm=iso>. access on 27 June 2020. Epub Aug 13, 2018. https://doi.org/10.1590/s010373312018280203.

Pepsic, Periódicos Eletrônicos de Psicologia. Disponivel em http://pepsic.bvsalud.org/. Acesso em: 31 de Julho de 2020.

Pina, José Augusto; Stotz, Eduardo Navarro (2015). Intensificação do trabalho e saúde dos trabalhadores: um estudo na Mercedes Benz do Brasil, São Bernardo do Campo, São 
Paulo1. Saude soc., São Paulo , v. 24, n. 3, p. 826-840, set. Disponível em $<$ http://www.scielo.br/scielo.php?script=sci_arttext\&pid=S0104-12902015000300826\&lng=pt \&nrm=iso>. acessos em 07 jun. 2020. https://doi.org/10.1590/S0104-12902015131966.

Sampaio, RF; Mancini, MC (2007). Estudos de revisão sistemática: um guia para síntese criteriosa da evidência científica. Rev. bras. fisioter., São Carlos , v. 11, n. 1, p. 83-89, Feb. Available from <http://www.scielo.br/scielo.php?script=sci_arttext\&pid=S1413-35552007000100013\&lng= en\&nrm=iso $>$. access on 07 June 2020. https://doi.org/10.1590/S1413-35552007000100013.

Santos, Sérgio Valverde Marques dos et al. (2017). Acidente de trabalho e autoestima de profissionais de enfermagem em ambientes hospitalares. Rev. Latino-Am. Enfermagem, Ribeirão Preto , v. 25, e2872. Available from <http://www.scielo.br/scielo.php?script=sci_ arttext\&pid=S0104-11692017000100328\&lng=en\&nrm=iso > access on 07 June 2020. Epub Apr 20, 2017. https://doi.org/10.1590/1518-8345.1632.2872.

Scielo - Scientific Electronic Library Online. Disponível em: https://pt.wikipedia.org/wiki/Scientific_Electronic_Library_Online. Acesso em: 31 de Julho 2020.

Silva, Mariana Pereira da; Bernardo, Marcia Hespanhol; Souza, Heloísa Aparecida (2016). Relação entre saúde mental e trabalho: a concepção de sindicalistas e possíveis formas de enfrentamento. Rev. bras. saúde ocup., São Paulo , v. 41, e23. Available from $<$ http://www.scielo.br/scielo.php?script=sci_arttext\&pid=S0303-76572016000100214\&lng=en \&nrm=iso>. access on 11 May 2020. Epub Dec 12, 2016.

Silva-Junior, João Silvestre; Fischer, Frida Marina (2015). Afastamento do trabalho por transtornos mentais e estressores psicossociais ocupacionais. Rev. bras. epidemiol., São Paulo , v. 18, n. 4, p. 735-744, Dec. Available from <http://www.scielo.br/scielo.php? script=sci_arttext\&pid=S1415-790X2015000400735\&lng=en\&nrm=iso $>$. access on 02 July 2020. https://doi.org/10.1590/1980-5497201500040005.

Vieira, Isabela (2019). Conceito(s) de burnout: questões atuais da pesquisa e a contribuição da clínica. Rev. bras. saúde ocup., São Paulo , v. 35, n. 122, p. 269-276, Dec. 2010 . Available from <http://www.scielo.br/scielo.php?script=sci_arttext\&pid=S0303$76572010000200009 \& \operatorname{lng}=\mathrm{en} \& \mathrm{nrm}=\mathrm{iso}>$. access on 09 Oct.

\section{How to cite this article (APA format):}

Costa, Aline Mesquita da; Maranhão, Thércia Lucena Grangeiro (2020). The Importance of Laboral Rest in Maintenance of Worker's Mental Health: A Systematic Review. Am. In. Mult. J., Jul to Oct. (9) 5, 216-237.

Received: 10/01/2020; Accepted: 10/05/2020. 